ISSN electrónico: 2172-9077

https://doi.org/10.14201/fjc201715185198

\title{
ÓPERAS FILMADAS: ESTUDIO COMPARATIVO DE DON GIOVANNI DE JOSEPH LOSEY Y JUAN DE KASPER HOLTEN
}

\section{Operatic Films: A Comparative Study of Don Giovanni by Joseph Losey and Juan by Kasper Holten}

Dra. Isabel VILLANUEVA BENITO

Visiting Researcher. University of California Los Angeles, (UCLA), United States of America

E-Mail: isabeluic@gmail.com, isabeluic@g.ucla.edu

(iD) https://orcid.org/0000-0001-7958-7059

Fecha de recepción del artículo: 30/03/2017

Fecha de aceptación definitiva: 23/10/2017

\begin{abstract}
RESUMEN
La adaptación de una ópera al medio cinematográfico, tradicionalmente se ha considerado un proceso complejo y controvertido desde el punto de vista artístico. Don Giovanni, de W. A. Mozart, es una de las óperas que más versiones audiovisuales ha generado durante los siglos XX y XXI, aunque son muy pocas las películas que finalmente se han llevado a la pantalla de cine. El interés de este trabajo se centra en comparar las versiones audiovisuales Don Giovanni, de Joseph Losey (1979), y Juan de Kasper Holten (2010). Mediante una metodología cuantitativa y cualitativa basada en el análisis de contenido, esta investigación reflexiona sobre el grado de intervención que ejercen el lenguaje y el formato audiovisual empleados en el proceso de reinterpretación del texto musical pre-existente.
\end{abstract}

Palabras clave: cine; ópera; adaptación; comunicación audiovisual; música; banda sonora.

\begin{abstract}
From an artistic point of view, the adaptation of an opera to the cinema, traditionally has been considered a complex and controversial process. Don Giovanni, of W. A. Mozart, is one of the operas that has generated more audiovisual versions during the centuries XX and XXI, although very few films have finally been taken to the screen. This paper is focused on comparing the audiovisual versions Don Giovanni, by Joseph Losey (1979), and Juan by Kasper Holten (2010). Through a quantitative and qualitative methodology based on content analysis, this research reflects on the degree of intervention exercised by the language and audiovisual format used in the process of reinterpretation of the pre-existing operatic text.
\end{abstract}

Key words: film; opera; adaptation; audiovisual communication; music; soundtrack. 


\section{LA ATRACCIÓN CINEMATOgRÁFicA DE DON GiOvanNi DE W. A. MoZART}

La adaptación de una obra musical a un soporte audiovisual como el cinematográfico o el videográfico ha constituido un modo de extender el espectáculo original fuera de los escenarios (Citron, 2000; Villanueva, 2014). Tradicionalmente, este proceso ha quedado condicionado por el espectáculo original, representado en los teatros (Auslander, 2008). En el caso concreto de las óperas filmadas, elementos esenciales de la obra original, tales como la música, la puesta en escena o el libreto, han determinado la estética y el lenguaje de las películas operísticas (Villanueva, 2014). Además de las herramientas audiovisuales básicas, la utilización de soportes y códigos específicos como el cinematográfico, televisivo o videográfico, acaban por transformar, desde el punto de vista semiótico, la ópera en cada una de las pantallas (Reason, 2004; Barker, 2012;).

En el ámbito de las óperas filmadas, nadie cuestiona que Don Giovanni de W. A. Mozart (KV 527) ha generado una gran atracción mediática durante todo el siglo XX. El libertino castigado o Don Juan (título original en italiano, Il dissoluto punito ossia il Don Giovanni) se trata de un dramma giocoso en dos actos con libreto en italiano del autor Lorenzo da Ponte. La ópera se basó inicialmente en la obra literaria de Antonio de Zamora titulada No hay plazo que no se cumpla ni deuda que no se pague, también conocida como Convidado de piedra. El estreno tuvo lugar en el teatro de Praga (actual Teatro Estatal) el 29 de octubre de 1787. El mismo Mozart describió la obra como parte del género de ópera buffa. Aunque a veces ha sido clasificada como cómica, la obra en realidad mezcla comedia, melodrama y elementos sobrenaturales en su argumento (Radigales, 2011; 2012, pp. 46-60). Desde su estreno, esta obra ha constituido una de las óperas más representadas en los teatros internacionales de los últimos 60 años (Goehr \& Herwitz, 2006, pp. xv-xix; Campana, 2009, pp. 140-151). Junto a otros títulos tan populares como la mozartiana Die Zauberflöte del mismo compositor o La Bohème de G. Puccini, Don Giovanni es una de las óperas que más adaptaciones audiovisuales ha generado en los diversos medios del cine, la televisión y el vídeo (DuMont, 2000, pp. 71-128; Remy, 1979)². De hecho, la obra llegó de forma muy temprana al cine, cuando en el año 1900 se realizó una breve adaptación musical y visual de una de las escenas de la ópera, con motivo de la Exposición Universal celebrada en París. Con una duración de 3 minutos, la filmación recogía la interpretación, en blanco y negro, del Barítono Victor Maurel (Wlaschin, 2004, p. 192). 20 años después de esta filmación se produjo la primera versión muda completa de la ópera. La película se estrenó en el año 1922 y según la información publicada por Ken Wlsachin (2004, pp. 188-194), no existe constancia ni registro del filme.

La primera adaptación cinematográfica de Don Giovanni que se conserva es la película inglesa que la compañía London Opera Company versionó para el cine en el año 1947, bajo la batuta del director Alberto Erede. A partir de entonces, Don Giovanni fue llevado a la gran pantalla en repetidas ocasiones y reinterpretado para televisión más de 12 veces durante la década de los 50 del pasado siglo. Como ejemplo de la elevada demanda mediática que se produjo en aquel periodo, se citan las cuatro versiones que se produjeron para los canales públicos de televisión en Italia, Viena y Austria en el año 1954 (Barnes, 2003). Debe apuntarse, no obstante, que la mayor parte de estas producciones se concibieron, no tanto como adaptaciones independientes, sino como extensiones de la obra teatral: constituían versiones grabadas desde los teatros de ópera para ser proyectadas en los cines, o bien representacio-

\footnotetext{
${ }^{1}$ Don Giovanni aparece en el número diez en la lista Operabase, de entre las óperas más representadas en todo el mundo. Consultar: www.operabase.com. Recuperado el 27 de octubre de 2016, de http://operabase.com/top.cgi?lang=en\#opera.
}

Ediciones Universidad de Salamanca / CC BY - NC ND $\quad$ Fonseca, Journal of Communication, n. 15, 2017, pp. 185-198 
nes en los sets de televisión de una producción musical concreta (Barnes, 2003). No eran consideradas películas completamente desligadas de la obra original en vivo, sino más bien películas obtenidas de la grabación de la ópera.

Fue en el año 1979 cuando se llevó a cabo la primera adaptación cinematográfica de la ópera Don Giovanni. Se trató de una coproducción entre Francia, Italia y Alemania, dirigida por Joseph Losey y liderada por Daniel Toscan du Plantier. El proyecto cinematográfico fue definido como una ópera filmada y, en la actualidad, es considerada una de las mejores obras de referencia en su categoría (Rushton, 1981, pp. 1, 5). Aunque la película no obtuvo el éxito esperado, fue alabada por la crítica y por el sector del público al que iba dirigida, minoritario y operófilo. Más adelante, en las décadas de los 80 y 90 del s. XX, se registraron más de 15 producciones sobre Don Giovanni en Europa y América, la mayoría de ellas, como se había dado en los años 50, adaptaciones para televisión de versiones escénicas de teatros como la Ópera de Zúrich, el teatro Regio di Parma o el Metropolitan Opera House de Nueva York.

Después del film de Losey, hasta el año 2010 no se volvió a estrenar en los cines una película sobre el mito de Don Juan con intenciones plenamente audiovisuales. La obra fue dirigida por Kasper Holten, escenógrafo reconocido por sus colaboraciones en The Royal Opera House (ENO) de Londres. Las productoras Blenkov \& Shonennmann Pictures y Eurofilm Studio estrenaron en 2011 esta adaptación audiovisual en Dinamarca y Gran Bretaña, bajo el título de Juan. La película se distribuyó de forma discreta y principalmente a través de festivales de cine independientes, como Seattle International Film Festival o Berlin International Film Festival.

El caso de Juan constituye un reflejo de la demanda que, en el siglo XXI, este título ha generado en el mercado musical y audiovisual, ya que sigue siendo una de las obras más populares de la historia del género operístico (Rubio \& Mancha, 2008; Will, 2011, pp. 32-34). Según los datos de Operabase, por ejemplo, en el año 2015 se planificaron 259 producciones de esta ópera en más de 40 teatros de ciudades europeas y americanas ${ }^{2}$. Gracias a los sistemas avanzados de grabación digital que se han ido incorporando en todos los teatros del mundo, la mayor parte de estas representaciones escénicas han quedado registradas en formato audiovisual. Sobre todo, se modifica en ellas el soporte en el que es apreciado el espectáculo. Sin embargo, en el proceso de adaptar un texto operístico pre-existente al medio cinematográfico, además del soporte, se transforma el lenguaje audiovisual empleado. Nuestro interés se centra en casos como Don Giovanni de Joseph Losey (1979) y Juan de Kasper Holten (2010), películas que, aunque se consideran adaptaciones de la ópera mozartiana, no han dependido de la obra original en su reinterpretación de la historia: han constituido proyectos audiovisuales independientes desde el punto de vista artístico.

Consultar: $\quad$ www.operabase.com.

Recuperado el 28 de octubre de 2016, de http: $/ /$ operabase.com/oplist.cgi?id $=$ none\&lang $=$ en\&is $=$ don + giovanni\&by $=\& l o c=\& s t y p e=a b s \& s d=28 \& s m=10 \& s y=2013 \&$ et vpe $=$ abs\&ed $=\& e m=\& e y=$. 


\section{OBJETIVO Y METODOLOGÍA}

En esta investigación se llevará a cabo un análisis comparativo de las dos películas, para determinar qué grado de intervención ejercen sobre el texto de la ópera de Don Giovanni, los distintos lenguajes y lógicas empleados en el proceso de audiovisualización. En concreto, el objetivo de este trabajo es analizar, en términos audiovisuales, las diferencias entre dos obras que utilizan el mismo soporte (en este caso cinematográfico) y que se nutren del mismo texto músico-escénico preexistente que les dio lugar. Desde un punto de vista mediático, el estudio comparativo de la propuesta cinematográfica de Joseph Losey de 1979, en relación a la adaptación audiovisual de Kasper Holten de 2010, pretende identificar algunas de las características que adoptan las adaptaciones de una ópera y sus convenciones estilísticas al lenguaje de los distintos medios (Radigales \& Cubas, 2017, pp. 136-146).

Para llevar a cabo el análisis de las películas, se ha escogido una parte narrativa de la obra original y un fragmento estrictamente musical: 1) el final del primer acto y 2) la obertura instrumental. Por un lado, el final del primer acto constituye un cuadro escénico compuesto por acciones dramáticas y personajes propios de un desarrollo narrativo en el cine: en una fiesta en el palacio de Don Giovanni, este intenta abusar de la criada Zerlina ante el revuelo y asombro de los invitados. Al ser descubierto, Don Giovanni acusa falsamente del acto a Leporello y consigue escapar. Esta escena presenta elementos que favorecen su mediatización en un soporte audiovisual: agilidad en la sucesión de acciones dramáticas; la presentación de un conflicto narrativo y su resolución; y la intervención de todos los personajes principales, entre otros (Will, 2011, pp. 32-59; Villanueva, 2014; pp. 320). Por otro lado, como complemento a este fragmento final del primer acto, se ha seleccionado para el análisis la obertura musical de las películas. Tradicionalmente la obertura ha constituido una pieza esencial de las óperas, de carácter estrictamente instrumental que, al ser representada en la escena del teatro, no suele ir acompañada de acción dramática, sino que sirve para ofrecer un anticipo del tono, el carácter narrativo y la intención artística en términos musicales (Walter, 2006, p. 429; Varon, 2012, p. 91). Sin embargo, trasladada a la pantalla, la obertura ha de ir acompañada de imágenes, ya que forma parte de la película (normalmente se corresponde con los títulos de crédito del filme) (Tambling, 1987, p. 16). Por lo tanto, este pasaje musical inicial debe acompañarse de una propuesta visual que, de igual modo, hable de la estética de la película y de la concepción mediática que del producto audiovisual hacen los autores. Se ha considerado interesante estudiar, en el proceso de una adaptación cinematográfica, cómo los directores han reinterpretado en términos audiovisual y narrativo la secuencia de apertura partiendo de un material estrictamente musical.

En el estudio comparativo de las dos películas se ha empleado una metodología cuantitativa y cualitativa combinada. Como método de investigación se ha empleado el análisis de contenido. Las categorías que nos ayudarán a hacer una lectura de las obras desde un punto de vista del lenguaje audiovisual son 1) la banda sonora musical, 2) el tipo de lenguaje audiovisual empleado y 3) la construcción del universo narrativo. Atendiendo a esta categorización, en un principio elaboramos, de forma deductiva, una lista amplia de variables, a partir de la bibliografía existente. En un segundo momento, y gracias a un primer visionado de las películas, que sirvió como pretest, acortamos esa lista y redefinimos las preguntas de control para que tuvieran una repuesta binaria, además de una valoración cualitativa para aquellos aspectos relevantes de la reinterpretación audiovisual. El trabajo se ha completado con una vasta revisión bibliográfica y hemerográfica sobre la producción audiovisual de 
Don Giovanni, así como con la consulta de los documentos públicos que las productoras de las películas han facilitado, tales como el documental Making Of que la productora Gaumont estrenó en el año 2006 en el que se recogen los testimonios de los participantes en el proyecto de Joseph Losey de 1979.

\section{Resultados}

Del estudio se extrajeron conclusiones en las categorías de análisis que resulta imposible recoger de forma exhaustiva en este apartado. Se expondrá a continuación una pequeña síntesis de aquellas valoraciones que ayudan a entender la transformación artística que la mirada cinematográfica imprime sobre el texto original de la ópera, tanto de la parte final del primer acto, como de la obertura (Radigales \& Cubas, 2017, pp. 136-146).

Antes de abordar los principales resultados obtenidos sobre el lenguaje audiovisual, debe señalarse que el análisis de contenido se realizó a partir de los DVD editados de las películas. Ambos soportes incluían material extra, adicional al contenido de la película. La información ofrecida por estos contenidos complementarios, en las adaptaciones de obras preexistentes como las novelas o las óperas, se ha mostrado altamente reveladora, ya que enriquece y condiciona al mismo tiempo la apreciación de una película nueva que parte de un texto ya conocido. Se cita, como muestra de ello, el significativo valor que tiene para los espectadores cinéfilos y operófilos conocer la experiencia sobre la filmación que vivenciaron los protagonistas tanto de la obra de Kasper Holten (2010) como de Joseph Losey (1979). En el documental de este último, por ejemplo, varios de los intérpretes del reparto principal, como la cantante Edda Moser, testificaron que la mayor parte de los problemas de dirección de actores que hubo en la película partían de la diferente visión que tenía un director de cine sobre la historia (en este caso el célebre Joseph Losey), que aquella que tenían los cantantes, experimentados en la ópera teatral y mucho más familiarizados con el texto original. Al conocer el subtexto de la producción, el espectador entiende no solo la dificultad de abordar una obra musical de reconocido prestigio internacional desde un soporte distinto y un lenguaje que se compone a partir de nuevas normas, sino que también entiende la relevancia artística necesaria para lograr resultados más propiamente audiovisuales, sin desvirtuar la belleza de la música y las convenciones de este arte (Esse, 2010, pp. 81-95). Mediante la visión positiva y educativa que ofrecen estos contenidos en ambas películas, se transforma y enriquece la apreciación mediática que pueden hacer de la obra los espectadores domésticos actuales. Se trataría, así, de un ejemplo de material extra que podría servir de referencia a cualquier tipo de adaptación audiovisual sobre una obra preexistente, habida cuenta de los recursos económicos necesarios, adicionales a la producción, que han de disponerse para desarrollar estos contenidos (Bongiovanni, 2017).

\subsection{FINAL DEL PRIMER ACTO: ÓPERA FILMADA VS. ADAPTACIÓN AUDIOVISUAL}

En primer lugar, de acuerdo al análisis del primer acto de la obra, tanto la versión de Losey del año 1979, como la de Holten de 2010, entrarían dentro de la categoría descrita como ópera filmada, es decir, la adaptación de una ópera al medio cinematográfico, desarrollada a partir de un planteamiento completamente diegético (Bourre, 1987; Tambling, 1994). Aunque existen excepciones, tradicionalmente en la ópera filmada suelen respetarse las notas esenciales de la obra original: el libreto, la música 
y la acción dramática puesta en escena (Parker, 1998, p. xi; Batta, 2005, p. 873; Adorno, 2006, pp. 2540; Radigales \& Cubas, 2017). Sin embargo, tras el análisis de las dos obras, se ha podido comprobar que estas condiciones son únicamente cumplidas por la versión de Joseph Losey y que, por lo tanto, podríamos hablar solo en su caso de ópera filmada. Kasper Holten, por el contrario, reinterpreta el texto original incorporando en él modificaciones significativas de acuerdo a los elementos compositivos de la ópera: la película presenta modificaciones y cortes en atención al libreto operístico; se producen elipsis musicales y arreglos instrumentales diferentes de la partitura de W. A. Mozart. Asimismo, Kasper Holten opta por adaptar el libreto original al idioma inglés e introducir en él actualizaciones gramaticales del texto: se incorporan alusiones a elementos del siglo XXI como las drogas sintéticas o los móviles; se emplean expresiones e insultos propios de un registro idiomático contemporáneo. Además, el autor decide traducir algunos de los recitativos cantados en la obra original e incorporarlos en forma de diálogos hablados o recitados. Por lo tanto, podría considerarse que en Juan se lleva a cabo una relectura a partir de la adaptación y de la contemporaneización de la ópera Don Giovanni. En concreto, aquello que confirma que Juan no es una ópera filmada al uso sino una adaptación para el cine son los metatextos, entendidos como aquellas sub-tramas añadidas por el autor que, aunque se manifiestan en muchos de estos productos al formar parte del proceso de remediación artística, en la versión de Holten cobran tal relieve que acaban transformando la trama principal y la construcción de los personajes protagonistas ${ }^{3}$.

La película de Joseph Losey, sin embargo, es desarrollada en un estricto estilo clásico, no solo en atención a la lectura que se realiza del texto original del libreto de Da Ponte, sino a través de elementos esenciales en el discurso de ambos lenguajes utilizados (el cinematográfico y el operístico), como son el empleo de la escenografía, la concepción de la gramática audiovisual y la preeminencia de la música sobre cualquier otro elemento estructural. Como Nicolas Seydoux afirma en el documental que la casa Gaumont realizó en 2006 sobre la producción de la obra, el objetivo inicial del proyecto no era realizar la filmación de una ópera, o una película sobre una ópera al estilo de otras producciones como la mozartiana Die Zauberflöte que años antes había realizado Irgmar Bergman, sino crear una auténtica ópera filmada, una adaptación operística utilizando el soporte cinematográfico que respetase jerárquicamente la estructura de la música original. Por lo tanto, antes de entrar en los resultados específicos de cada una de las categorías, debe reconocerse una distinción apriorística entre la ópera filmada al uso que plantea Joseph Losey, y la adaptación que propone Kasper Holten en su versión de 2010.

\subsubsection{BANDA SONORA: PERFECCIÓN MUSICAL $V S$. VEROSIMILITUD AUDIOVISUAL}

En relación a la concepción de la banda sonora, existen diferencias significativas en ambas películas. Por un lado, Joseph Losey optó por el completo doblaje de la banda musical, tal y como ya había puesto en práctica en otras producciones similares (Palmer \& Riley, 1993; Gardner, 2004). Se grabó previamente, por separado, el acompañamiento orquestal junto con las voces de los protagonistas, dirigidas bajo la batuta de Lorin Maazel. Los cantantes se doblaron a sí mismos en una concepción de sonido que, según la propia productora Gaumont, priorizaba el texto musical por encima de cualquier

\footnotetext{
${ }^{3}$ Citamos un ejemplo: en el primer acto se produce una metadiégesis en la que queda enmarcada toda la estructura narrativa de la película. El personaje de Juan, un reconocido artista del siglo XXI, acaba identificándose con el papel de Don Giovanni hasta que le lleva a la autodestrucción.
} 
necesidad audiovisual, en términos de verosimilitud. El proyecto, así, quiso recrear la perfección musical de Mozart mediante la utilización de una banda sonora pregrabada en estudio, en alta calidad. Aunque en la versión final de la película se incorporó un diseño de sonido diegético con efectos realistas para hacer funcionar el filme en términos cinematográficos, la música se mantuvo en un primer plano en la mezcla final, sin respetar las profundidades de campo derivadas de la escenografía. Especialmente en determinados pasajes como las arias y los duettos, en los que se producían acercamientos de la cámara a los personajes, esta decisión provocó cierta falta de correspondencia entre la gestualidad vocal y la banda sonora. Como los propios cantantes manifestaron en el documental 27 años después de la producción, las directrices que recibían sobre la actuación facial perseguían un naturalismo y una gestualidad audiovisual que difícilmente podían corresponderse con la grabación musical pre-existente. Además, el hecho de que en la película Don Giovanni se doblase toda la banda de sonido tuvo consecuencias también en el lenguaje cinematográfico, ya que obligó al empleo de un tipo de planos más abiertos para no evidenciar esta falta de verosimilitud, manifestada no tanto en la sincronización de los labios al cantar, sino en la corporalidad que demandaban las inflexiones vocales de los pasajes musicales. Dicha corporalidad resulta un elemento clave para transmitir el realismo diegético de una película a partir del que se produce, en los espectadores, la inmersión narrativa en la obra (Radigales, 2012).

Por otro lado, la versión de Kasper Holten optó por un planteamiento plenamente diegético, en el que los personajes cantaban todas las partes del libreto mientras actuaban para la cámara en tiempo real durante el proceso de grabación. La música no se incorporó en la postproducción, sino que se registró en el propio rodaje y posteriormente fue editada y perfeccionada. Si bien este sistema no asegura una calidad musical absoluta en términos de definición, se considera óptimo para conseguir una mayor verosimilitud narrativa desde el punto de vista audiovisual, así como para dar la misma relevancia a las acciones dramáticas que a las pautas y a la estructura que marca la música (Cachopo, 2014, pp. 315-329). Este detalle, aunque pequeño, se considera muy significativo en la tradicional adaptación operística a la pantalla: en Juan las expresiones faciales adoptaron una naturalidad difícil de alcanzar en el teatro cantado. La dirección de actores, en esta película, se manifiesta especialmente audiovisual (en determinados momentos, incluso, al espectador se le olvida que los personajes están cantando). En el siglo XXI, los avances tecnológicos en los sistemas de grabación en HD están haciendo posible que, en las filmaciones musicales, más que nunca, se alcance un realismo audiovisual equiparable a otros subgéneros sin renunciar a la calidad sonora que exige la producción de este tipo de obras. La adaptación dirigida por Kasper Holten es una buena muestra de ello.

\subsubsection{LENGUAJE AUDIOVISUAL: CINE CLÁSICO VERSUS ESTÉTICA VIDEOGRÁFICA}

$\mathrm{Al}$ analizar el final del primer acto, también puede comprobarse cómo ambas películas emplean el lenguaje audiovisual con distinta finalidad. Juan, de Kasper Holten, utiliza en el montaje planos cerrados (generalmente planos medios y de conjunto), en los que cobran especial relevancia las miradas de reacción de personajes, los primeros planos y los movimientos de cámara inmersivos, de acercamiento hacia los gestos faciales de los personajes (como los zooms). Esta planificación facilita el constante traspaso metadiegético al mundo interior del personaje (que distorsiona su propia realidad) y que, desde la mirada del espectador, modifica la perspectiva desde la que se cuenta la historia. En el lenguaje empleado en Juan, también se utiliza el recurso de la cámara en mano potenciando una estética más cercana al vídeo que al cine: los planos no son fijos, sino que se balancean ligeramente para potenciar 
el realismo, la inmediatez y el efecto improvisado de la grabación (Vieytes, 2008, pp. 61-64). Al mismo tiempo, el hecho de grabar en un sistema digital en HD y no con una cámara cinematográfica, refuerza esta estética propia del vídeo, más familiar e imperfecta, acorde con la escenografía contemporánea que se eligió para ambientar la película. Dicha estética moderna y videográfica se sitúa más cerca de la rutina de los espectadores, acostumbrados a consumir videos domésticos similares en la televisión y los medios digitales. Sin duda, este acercamiento estilístico a la vida diaria del espectador puede ayudar a un arte convencional como la ópera a mostrarse actualizado y cercano, no lejano y elitista, a ojos de los públicos mediáticos (Lacasa \& Villanueva, 2012, pp. 413-418).

Por otro lado, el ritmo de montaje, así como el tipo de planos empleados en la cinta parecen responder a un criterio fundamentalmente narrativo. Gracias a él se potencia no solo la historia principal del libreto, sino también las sub-tramas añadidas a la música que consiguen dar relieve psicológico a los personajes. Para ello, el autor utiliza 200 planos en el montaje del final del primer acto. Esta cantidad, unida a una combinación coherente entre planos medios y movimientos ligeros de la cámara, favorece una percepción más dinámica de la acción dramática que aquella que se hace de la escena original de Losey (construida a partir de 55 planos).

Figuras 1 y 2. Capturas del tipo de planos empleados en el final del primer acto de Juan y Don Giovanni

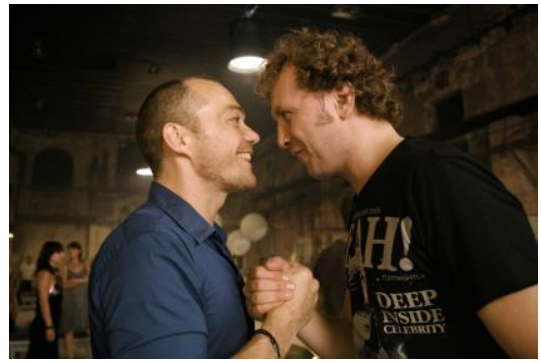

1. Juan, de Kasper Holten (2010)

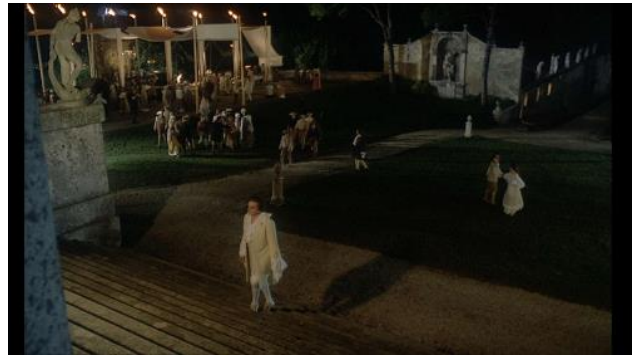

2. Don Giovanni, de Joseph Losey (1979)

Como puede comprobarse en las figuras 1 y 2, la planificación audiovisual empleada en 1979, en Don Giovanni de Joseph Losey, recurre al lenguaje clásico propio del cine de ambientación histórica, en el que cobra especial relevancia el contexto en el que se produce la narración (Gardner, 2004). A diferencia del proyecto de Holten, Losey optó por contar la escena a partir de grandes planos generales que sirven de referencia espacial y que, en el lenguaje audiovisual clásico, generalmente han ido acompañados por músicas en las que existe una gran densidad armónica, una pluralidad de texturas, o un movimiento acelerado, como corresponde al momento finale del primer acto (Nieto, 2010; Citron, 2005, pp. 204-206). A partir de esta planificación abierta y grandilocuente, acorde con la ambientación escénica y la localización escogidas (los edificios italianos de Palladio de Venecia y de Veneto), el autor utiliza planos de conjunto y de personaje para acercarse esporádicamente a la acción dramática (Gardner, 2004).

En términos generales, en la versión de 1979 se emplea una planificación con menor movimiento de cámara. Este montaje cinematográfico, de un estilo clásico, no solo se construye a partir de planos fijos mezclados con lentos travellings y paneos de seguimiento apenas perceptibles (a excepción del movimiento acelerado hacia los rostros de Zerlina y Don Giovanni al comienzo de la escena), sino 
que dicho estilo se manifiesta también en la escenografía escogida para la película. Únicamente se mueve la cámara para realizar un seguimiento de las coreografías de los cantantes en conjunto. Asimismo, Joseph Losey recurrió a los constantes travellings de acompañamiento de personaje, sobre todo en las arias y pasajes en los que se produce una reflexión interna. Estos ligeros movimientos de cámara, a diferencia de la versión de Holten, no están sujetos a criterios escénicos o narrativos, sino que responden a las inflexiones de la música de Mozart. En esta misma línea y en atención al ritmo de montaje, Losey parece emplear un criterio eminentemente musical, en el que los cambios de plano son marcados por el desarrollo de la música y del canto. Llama la atención cómo el autor introduce el recurso de avanzar las modulaciones musicales con un corte de plano en la imagen, para preparar al espectador en la escucha de la historia. Este detalle aporta cierto sentido de coreografía que conecta directamente con la experiencia operística en los teatros, donde toda la acción dramática de la ópera es estrictamente planificada al servicio de la música (Villanueva, 2014). Losey emplea 55 planos para construir la escena musical. Esta cantidad es significativamente inferior a la utilizada por Holten en su versión videográfica: se crea un ritmo de montaje más lento, pero más acorde con la ambientación histórica empleada tradicionalmente en las óperas filmadas (Bourre, 1987).

Finalmente, sobre el tipo de ángulos empleados en las filmaciones, debe mencionarse que en ambas películas se aprecia una intencionalidad narrativa en el uso de planos no frontales, como los picados y contrapicados. En la versión de Kasper Holten, muchos de ellos además responden a un criterio estilístico basado en la movilidad de la imagen hacia el mundo interior del personaje. Por su parte, en la película de Joseph Losey, la angulación constituye un elemento de subjetivación de la historia y responde al foco desde el que se cuenta la acción dramática en cada escena. Se cita como ejemplo el momento en el que Zerlina es rescatada por el pueblo de las manos de Don Giovanni: toda la acción sucede en dos pisos de la parte interior del palacio, separados por una pequeña escalera, donde un plano picado sobre los invitados indica, además de la perspectiva de la cámara, la situación dominante del protagonista antes de su huida.

Figura 3. Plano contrapicado de Don Giovanni después de ser descubierto por los invitados

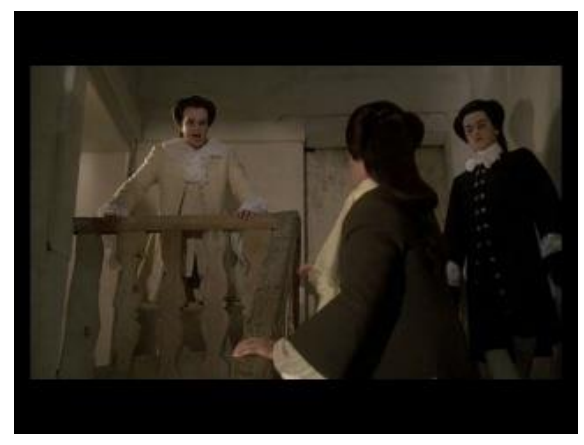

Don Giovanni de Joseph Losey. Finale acto 1.

Losey resuelve la escena final mostrando nuevamente una clara intención narrativa en la angulación, al colocar al protagonista en un contrapicado abierto, frente al pueblo (figuración colectiva), situado en picado a lo largo de las escaleras del palacio. Puede comprobarse, en estos ejemplos, que la elección de un tipo de ángulos asociados a significados narrativos rompe la apreciación frontal propia 
de los teatros y construye una dimensión en $360^{\circ}$ mediante la que el espectador conecta de un modo más íntimo y subjetivo con la historia. El empleo de este tipo de recursos y asociaciones permite facilitar la lectura audiovisual de películas, como las operísticas, construidas a partir de materia musical preexistente.

\subsubsection{UNIVERSO NARRATIVO: EL CINE AMPLÍA Y EMULA EL MUNDO DE LA ÓPERA}

En relación a la construcción del universo narrativo, las dos películas también se consideran muy diferentes, si bien es cierto que en ambas se advierte cierta intención de prolongar del universo diegético en el que viven los personajes y se desarrollan las tramas. Por un lado, el universo narrativo de Juan no acaba en las acciones externas de los personajes principales, sino que se prolonga a través de la relación que el protagonista establece psicológicamente entre el exterior y su mundo interior. Por otro lado, la planificación empleada por Losey y la elección de unas localizaciones panorámicas, simbolizan la trascendencia del drama: un hombre que se enfrenta a un destino sobrenatural ya escrito que, por más que quiera evitar, es más grande que su propia vida. Ambos planteamientos, el de Joseph Losey, externo y grandilocuente, así como el de Kasper Holten, más íntimo y psicológico, consiguen prolongar el universo narrativo de los personajes más allá de la música y el libreto propuestos por la ópera original.

Figuras 4 y 5. Ejemplos de profundidad de campo y extensión del universo narrativo

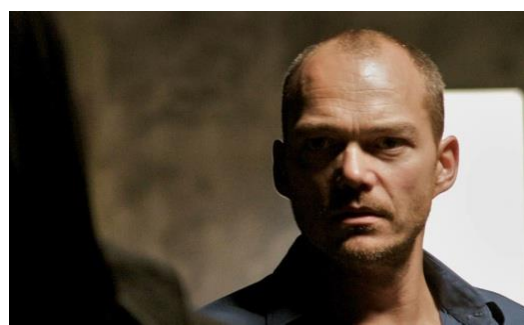

4. Juan, de Kasper Holten (2010)

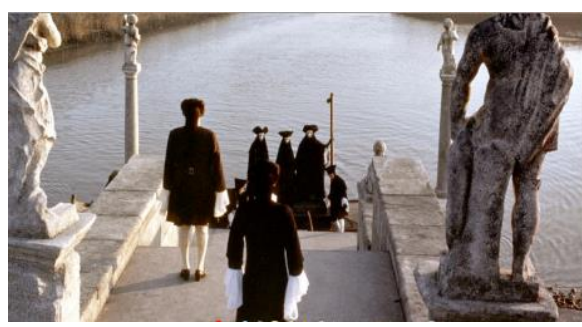

5. Don Giovanni, de Joseph Losey (1979)

Sobre la escenografía, también conviene resaltar la inteligencia con la que ambas versiones juegan con la profundidad de campo. Más evidente si cabe en la versión de 1979, en la composición de los cuadros narrativos se establece una jerarquía de acciones en las escenas, ordenada de acuerdo a un punto de fuga del cuadro, en la mayoría de los casos muy lejano. En ambas películas, la profundidad de campo se consigue gracias al empleo de localizaciones panorámicas (la nave industrial que recrea el taller del artista en Juan, así como los edificios de Palladio de Venecia y de Veneto en la versión de Losey). El efecto de prolongación espacial también es potenciado por los desplazamientos de la cámara, creados para conseguir la mayor tridimensionalidad posible en el espacio escénico utilizado.

No debe concluirse este apartado sin comparar la presencia del mundo de la ópera y sus convenciones estilísticas en el universo narrativo de ambas películas (Radigales, 2017). De hecho, una de las diferencias ontológicas que plantean las dos versiones tiene que ver con la alusión al espectáculo operístico en sí mismo. En Juan, el mundo de la ópera está presente de una forma literal: toda la trama 
transcurre en torno al ambiente de un teatro y sus cantantes, al mismo tiempo que se incorporan cameos de divos famosos en el mundo real (como la aparición de Plácido Domingo). Por su parte, en la versión de Joseph Losey, la alusión al mundo de la ópera y sus convenciones se manifiesta de una forma indirecta, a partir de elementos como una escenografía teatralizada, los movimientos escénicos coreografiados con la música y el empleo de un atrezzo y un maquillaje mucho más cercanos al mundo de la ópera que al del propio cine. De hecho, una de las interpretaciones históricas que se ha hecho de la película es, precisamente, el intento deliberado de reconstruir una ópera al más puro estilo teatral, pero incorporando en el filme aquellos elementos que el medio cinematográfico es capaz de potenciar de un modo genuino, como el empleo de localizaciones reales que no pueden usarse en un teatro, o la movilidad de la cámara, entre otros (Rushton, 1981).

\subsection{OBERTURAS: SIMBOLISMO FRENTE A DIMENSIÓN NARRATIVA}

Finalmente, se considera interesante apuntar algunas de las conclusiones extraídas del análisis las oberturas instrumentales de las películas. Como ya se ha manifestado en el estudio comparativo del final del primer acto, también en la secuencia de apertura, tanto la finalidad de la misma, como el planteamiento narrativo son muy distintos en ambas obras. Por un lado, Joseph Losey utiliza la obertura para llevar a cabo una majestuosa presentación de los personajes principales, así como para situar en el periodo histórico y el lugar (Italia) en el que va a tener lugar la ambientación. Todo ello lo realiza a través de un complejo plano secuencia reconstruido en un estilo tradicionalista. Gracias al extenso trabajo de documentación histórica de la producción, tanto la época como el lugar se corresponden con la obra original de W. A. Mozart. Además, en esta presentación el autor incorpora imágenes y sonidos del mar (antes del comienzo de la obertura sobre los créditos, y antes de mostrar la llegada del barco al palacio) que no solo indican el estilo veneciano en el que se va a desarrollar la acción dramática, sino que, principalmente, emulan en un tono simbólico, la majestuosidad y la trascendencia del destino escrito sobre Don Giovanni.

Por el contrario, la obertura propuesta por Kasper Holten es, desde un punto de vista narrativo, más compleja y menos simbólica: el personaje principal, Juan, presencia en un teatro la versión operística de Don Giovanni, en la que se interpreta la obertura de la obra. El punto de partida musical es diegético, pero a medida que transcurren las imágenes, el espectador sigue escuchando el pasaje de la obertura en tiempo real, mientras se produce una elipsis temporal para el personaje principal (ya que se ve cómo Juan disfruta del trascurso de los distintos actos de la ópera). El concepto del destino también se manifiesta en esta versión, pero no de un modo simbólico, sino narrativo, ya que el personaje vaticina su propio devenir al cerrar los ojos en un momento determinado e imaginar que se encuentra con su amante. Se construye así el conflicto inicial de la película, en el que queda implícita la presentación de los personajes de Juan y de Doña Ana a partir de un juego de cruce de miradas. La parte final del pasaje orquestal transcurre fuera del teatro, mediante una secuencia en la que puede apreciarse claramente la infidelidad del protagonista que le llevará a la muerte. Tanto la idea del destino como la subjetivación del personaje principal se construyen utilizando este tipo de pasajes metadiegéticos que constituirán un recurso empleado a lo largo de toda la obra, para indicar al espectador cuándo el foco de la historia es objetivo y cuándo muestra la psicología interna de Juan. El resultado de este recurrente cambio de foco crea un juego entre tres planos diegéticos distintos y complementa- 
rios: 1) la música interpretada en el teatro, que pasa a ser extradiegética en el momento en el que no se corresponde con la narración; 2) la diégesis propia de la realidad objetiva que vive el protagonista; y 3 ) la perspectiva metadiegética del mundo interior del personaje en los momentos en los que pierde parcialmente el control de su realidad. Aunque complejo, este planteamiento ayuda a entender toda la película y otorga libertad expresiva al director, al no tener por qué mostrarse verosímil con los hechos narrados por la música, y al no quedar condicionado por la estructura textual excesivamente lenta o rígida para un medio como el videográfico, en determinados pasajes de la ópera original.

\section{CONCLUSIONES}

La adaptación a la pantalla de una ópera de referencia internacional como Don Giovanni exige no solo un conocimiento profundo de las notas esenciales de la obra mozartiana original, sino debatirse entre decisiones formales que determinan su resultado desde el punto de vista audiovisual: respetar sus componentes primarios o adaptarlos al nuevo lenguaje; priorizar la música o la acción dramática; reproducir fielmente la historia o transformarla para facilitar la lectura al espectador cinematográfico; optar por una ambientación histórica o transportarla a un nuevo contexto, etc. En el caso concreto de las óperas filmadas, de esas decisiones formales dependerá que las adaptaciones audiovisuales atraigan nuevas miradas sin perder al público más familiarizado con el arte, convencional y fiel a la obra teatral. Sin embargo, la discusión entre fidelidad y originalidad tiene muchos matices, como se ha podido comprobar en este análisis: la película de Juan propone este acercamiento a nuevos públicos; orientada al sector más operófilo, Don Giovanni ensalza y respeta al dictado la ópera de Mozart.

Este trabajo se ha centrado en la observación de algunos de los elementos del lenguaje audiovisual y en la experiencia estética que estas dos películas provocan, unidas por un mismo texto y separadas por un cuarto de siglo. La versión de Joseph Losey constituye una obra de arte en el subgénero musical, en la que se potencian elementos propios de la semiótica cinematográfica, especialmente el majestuoso empleo de las localizaciones, la planificación o el montaje. Desde un punto de vista audiovisual, cabe preguntarse si la fidelidad total a la obra musical puede condicionar parcialmente el empleo de más recursos propios del cine que, en el siglo XXI, hubieran favorecido un resultado algo menos estático y teatral. Por su parte, Juan, de Kasper Holten, constituye una adaptación videográfica que utiliza recursos estéticos cercanos al espectador doméstico. La película propone interesantes fórmulas en relación a la construcción del universo narrativo para conseguir un resultado más dinámico, contemporáneo y realista. Mediante un estilo audiovisual familiar, imperfecto y actual, Juan también constituye un ejemplo de cómo una adaptación operística en la pantalla puede utilizarse para avanzar hacia una comunicación y educación de la ópera (con sus historias universales) entre las nuevas audiencias mediáticas. Sin embargo, en la película también se tomaron decisiones sobre el texto original que alejaban drásticamente el resultado de la ópera de W. A. Mozart. No debería olvidarse que Don Giovanni es una de las piezas más relevantes de la historia de la música. Por lo tanto, cabría preguntarse si estas decisiones favorecen su aceptación o ponen en riesgo no solo el resultado artístico, sino la lectura que de la nueva versión pueden hacer las audiencias musicales. 


\section{BIBLIOGRAFÍA}

Adorno, T. W. (2006). Ópera burguesa. En Escritos musicales (pp. 25-40). Akal.

Auslander, P. (2008). Liveness: Performance in a mediatized culture. London: Routledge.

Batta, A. (2005). Ópera. Barcelona: Könemann-Tandem Verlag GmbH.

Barker, M. (2012). Live to Your Local Cinema: The Remarkable Rise of Livecasting. London: Palgrave Macmillan.

Barnes, J. (2003). Television opera: the fall of opera commissioned for television. London: Boydell Pr.

Bongiovanni, M. (2017). Entrevista realizada por una de las autoras a la responsables de las retransmisiones en HD para los cines del Metropolitan Opera House de Nueva York. Nueva York, 6 de octubre de 2017.

Bourre, J. P. (1987). Opéra et Cinema. Paris: Artefact.

Cachopo, J. P. (2014). Opera's Screen Metamorphosis: The Survival of a Genre or a Matter of Translation? The Opera Quarterly, 30(4), 315-329.

Campana, A. (2009). To look again (at Don Giovanni). The Cambridge Companion to Eighteenth-Century Opera (pp. 140-151). http://rephip.unr.edu.ar/bitstream/handle/2133/1693/Trabajo Completo PN48.pdf? sequence=1

Citron, M. (2005). Subjectivity in the Opera Films of Jean-Pierre Ponnelle. Journal of Musicology, 22(2), pp. 203-240.

DuMont, M. (2000). The Mozart-Da Ponte Operas: An Annotated Bibliography (Vol. 81). United States of America: Greenwood Publishing Group.

Esse, M. (2010). Don't Look Now: Opera, Liveness, and the Televisual. The Opera Quarterly, 26(1), 8195.

Gardner, C. (2004). Joseph Losey. Manchester University Press.

Goehr, L. y Herwitz, D. A. (Eds.). (2006). «The» Don Giovanni Moment: Essays on the Legacy of an Opera. New York: Columbia University Press.

Lacasa, I. y Villanueva, I. (2012). Actualización de la ópera y sus nuevos modelos de comunicación digital. El profesional de la información, 21(4), 413-418.

Nieto, J. (2010). Una historia oral con J. Nieto/Entrevistador: autora y compositor en el Postgrado de composición de música aplicada 2009-2010 en el Conservatorio Superior de Música Liceo. Barcelona.

Opera and Film: can this unión be saved? (2005). The Washington Post. Recuperado de http://www.washingtonpost.com/wp-dyn/articles/A56556-2005Jan7.html

Palmer, J. y Riley, M. (1993). The Films of Joseph Losey. Cambridge University Press.

Radigales, J. (2011). Literatura i òpera: Don Giovanni de WA Mozart, julio 2011.

Radigales, J. (2012). De Don Joan a Don Joan: Joan Maragall i Don Giovanni. Marges. Els: revista de llengua i literatura, 96, 46-60.

Radigales, J. y Cubas, Y. B. (2017). Ópera, texto y audiovisualización. Estudio de un caso: «El anillo del Nibelungo». Tropelias: Revista de Teoría de la Literatura y Literatura Comparada, 27, 136-146.

Reason, M. (2004). Theatre Audiences and Perceptions of «Liveness» in Performance. Participations, $1(2)$.

Roselli, J. (1998). La ópera como acontecimiento social. En Parker, R. (ed.), Historia ilustrada de la ópera. Barcelona: Paidós Ibérica. 
Rubio, J. C. M. (2008). El romanticismo de Don Giovanni desde los medios audiovisuales hasta el aula de educación musical. Ensayos, 21, 103-123

Rushton, J. (Ed.). (1981). WA Mozart: Don Giovanni. New York: Cambridge University Press.

Tambling, J. (1994). A night at the Opera: Media Representations of Opera. London: John Libbey and Co.

Vieytes, M. (2008). A través del video: viaje al otro lado del cine. El Amante Cine, 193, 61-64.

Villanueva Benito, I. (2014). La mediatización audiovisual de la ópera como proceso de apertura a nuevos públicos: El caso de la Obra Don Giovanni de WA Mozart. Tesis Doctoral.

Will, R. (2011). Zooming In, Gazing Back: Don Giovanni on Television. The Opera Quarterly, 27(1), 3265.

Wlaschin, K. (1997/2004). Opera on Screen. A Guide to 100 Years of Films and Videos. Los Angeles: Beachwood Press.

Zoppelli, L. (1994). L’opera come racconto. Venezia: Marsilio.

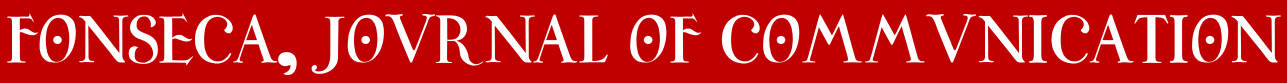

